\title{
Ethical Decision Making of Future Mexican Managers
}

\author{
Maria A. Leach-Lópeza*, Claire A. Stammerjohan ${ }^{b}$, William W. Stammerjohanc, Megan M. \\ Leach $^{d}$ \\ aschool of Accountancy, University of Southern Mississippi, United States of America, maria.leach@usm.edu \\ ${ }^{b}$ School of Management, University of Louisiana Monroe, United States of America, stammerjohan@ulm.edu \\ 'School of Accountancy, Louisiana Tech University, United States of America, wstammer@latech.edu \\ ${ }^{d}$ School of Accountancy, University of Southern Mississippi, United States of America, megan.leach@usm.edu \\ ${ }^{*}$ Corresponding author.
}

Received: 24 January 2018, revised: 9 June 2018, accepted: 15 June 2018, published: 15 June 2018

\begin{abstract}
This study explores the ethical decision-making process of future Mexican managers by examining a sample of Mexican college business students. Correlations and regression analysis were utilized to analyse survey data. Six ethical frameworks are discussed and evaluated along demographic variables. Findings do not support the influence of gender, education level, or work experience on the ethical decision-making process. The Mexican sample is most strongly influenced by the hermeneutical framework, the belief that they should act as a moral compass in making ethical decisions related to their organization. Results indicate that the process is different between the US and Mexico.
\end{abstract}

Keywords: ethics, Mexico, decision making, ethical frameworks, amoral, egoism, deontology, utilitarianism, hermeneutical

JEL codes: $M 1, M 12, M 16, M 40, M 53, M 54$

\section{INTRODUCTION}

The purpose of this study is to explore the ethical decision-making process of future Mexican managers. We pursue this purpose by examining a sample of Mexican college business students and then comparing the results with Keller, Smith, \& Smith (2007)'s examination of US accounting students. Much like Keller et al. (2007), we find little evidence of supporting the influence of gender, education level, and/or work experience on the ethical decision-making process. However, what we do find is much more consistent with Anderson (2018). We find the ethical decision-making process, and the factors individuals rely on in that process are much different between the US and Mexico. We find significant differences in the individual impact of six ethical frameworks on the ethical decision-making process of individuals, and in the rank order of importance of these ethical frameworks on the ethical decision-making process. While Keller et al. (2007) found the greatest impact from the reliance on religious reasoning among their US sample, our Mexican sample was most strongly influenced by the hermeneutical framework, i.e., the belief that they should act as a moral compass in making ethical decisions related to their organization.

The need for a better understanding of the Mexican work and management environment within the US is well documented in the extant literature, e.g., Mexico represents a significant component in the value chain of many US companies (Anderson, 2018). Furthermore, ethics, and the decline in ethical behavior, is a major issue facing business (Holland \& Albrecht, 2013). In their worldwide survey of academics, Holland \& Albrecht (2013) found that the decline in ethical behavior and globalization, including the influence of culture, were factors recognized by academics as important to the study and teaching of ethics. The impact of culture is also documented in work by Doh, Husted, Matten \& Santro (2010), Franke \& Nadler (2008), and Su (2006). Finally, in a study of US perceptions regarding the ethical behavior of individuals within the US, Mexico, India, and China by Khera (2010), the US respondents perceived Mexico as the most unethical among the four countries. 
The combination of the importance of Mexico to American businesses, the importance of ethics in the business environment, and the perception of ethics in Mexico, make it ever more important for US companies doing business in Mexico to have a better understanding of the ethical decision-making process of future Mexican managers.

We adapt the survey employed by Keller et al. (2007) to capture the impact of six ethical frameworks on the ethical decision-making process of individuals: amoral (lack of moral reasoning), egocentric (self-serving), religious (reliance on religious guidance), deontological (reliance on rules), utilitarian (greater good), and hermeneutical (acting as the moral compass). Understanding the impact of these frameworks and understanding the differences in the impact of these frameworks between our Mexican sample and the US findings of Keller et al. (2007) provide insight for US companies trying to better understand the ethical decisionmaking process of future Mexican managers.

The remainder of the paper is organized as follows: a review of the relevant ethics literature and the definitions and literature supporting each of the six frameworks employed in our study; the development of our hypotheses; a description of the data and methodology; the analysis and results; a discussion of the results and managerial implications, and a concluding section that summarizes the impact of the results, acknowledges the limitations, and provides suggestions for future research.

\section{SIX ETHICAL FRAMEWORKS}

Ethics are associated with behavior and how personal perspectives affect that behavior. Ethics help managers embrace a set of moral values that guide the cognitive process in decision making (Ardelean, 2015). Conflicts between the manager's personal interest and the public interest may be solved through the practice of an ethical framework which might dictate how the ethical dilemma should be resolved. Like Keller et al. (2007), the current study explores the impact of six ethical frameworks that may guide the ethical decisions made by managers, or in the present case, future managers.

\subsection{Amoral}

In this ethical framework there is no framework. In this case, the person would make ethical decisions without the guidance of an ethical framework. It could be said that the amoral ethics framework is 'none.' This amoral framework posits that business decisions and ethics are not related.

\subsection{Egoism}

In this framework, what is good for the decision maker guides the decision, and this might be the ethical approach that managers ultimately follow (Keller et al., 2007). This egoistic framework of ethics reduces predictability and consistency of decisions. Managers are supposed to maximize profits by minimizing costs, but will the good of the company serve the needs of the community at large? Egoism as a framework for ethical decision making might not be functional. According to Keller et al. (2007), "two possibilities exist for ethical outcome on the basis of egoism: 1) a clean conscience does have a certain utility to the ethical person and 2) ego driven action is 'just' action because the system of economics supported by this self-service is the most 'just' system" (p. 301). Vodonick (2016) argues that pragmatism (egoism) is the most appropriate approach in decision-making when faced with the ethical question of 'what is to be done.' Vodonick (2017) further believes that pragmatism (egoism) is the only framework where the results of a decision might either conflict or harmonize with the manager's values. That pragmatism (egoism) justifies past or future actions in relationship to one's values in determining whether the actions are good or bad.

\subsection{Religious}

This framework is dependent on a supreme being, who sets standards of right and wrong. "[R]eligion is arguably the broadest basis that society has for ethics and provides the internal justification for many ethical acts such as providing safe working conditions, treating employees fairly, and protecting the environment" (Keller et al., 2007, p. 302). Melé (2015) reports that religious approaches in business ethics research have increased. He reports that empirical and conceptual research have shown the influence of religious faith on several business issues, and this influence is reported from the perspective of different religions. Melé (2015) believes that religion in the study of business ethics will be more relevant in the future for various reasons. Some of those reasons are 1) increased interest from academia, 2) the logical fit between religions and philosophical approaches, and, very importantly, 3) a globalization that allows for better knowledge of other cultures in which religions play a very important role. Garrett (2016) examines faith as a solution and a foundation for business ethics that can 
support a commercial practice that could contribute to human development and satisfaction of human needs, as opposed to reliance on self-interest and the maximization of material gain.

\subsection{Deontology}

Under this ethical framework the decision maker does not worry about the consequences of the decision but simply focuses on making a decision. The action itself is what matters, following a code or a standard without having to worry about what is best. The manager follows standards and regulations without considering whether those standards are inadequate and thus could be considered unethical. "The bottom line is that fallible human beings will produce fallible ... standards" (Keller et al., 2007, p. 303). Deontology focuses on the notion that the means justify the results. In a study of Malaysian managers, Khalid, Eldakak, \& Loke (2017) found that deontology has a strong impact on ethical reasoning.

\subsection{Utilitarianism}

Under this framework, the correct decision or action is the one that will bring the most happiness to those affected. It advocates that the right decision brings about the most overall good. Epstein \& Spalding (1993) defined this ethical framework as "... striving to make decisions that optimize the greatest possible good ... for the greatest number of people ..." (p. 229). Keller et al. (2007) believe that this ethical rule is flawed because it allows excesses to be justified. Ultimately, the manager is faced with having to decide what is the greatest good for the greatest number. Frederiksen (2012) discusses and rejects conclusions about utilitarianism and its relationship to capitalism. He argues against claims that utilitarianism is merely a sophisticated simple majority vote. Moehler (2013) develops a framework that justifies utilitarianism as compatible with individual rational agency.

\subsection{Hermeneutical}

In this ethical decision-making framework, the manager has an ethical guide that is higher than profit maximization and self-interest. A corporation is a legal entity without consciousness, so the manager must act as the corporation's moral conscience. As such, the manager becomes the firm's soul and the decision making has ethical implications. Managing the business makes the managers accountable to society at large. "The fiduciary relationship between [the manager] and corporation formalizes the trust of the corporation that its identity will be faithfully rendered" (Keller et al., 2007, p. 304). This ethical framework then recognizes that there are standards and rules that managers are guided by and would likely follow; but, under the hermeneutical framework of ethics, the manager may deviate from the standards if those standards prevent the manager from giving an adequate representation of a corporation's reality. Under this framework, a person would have the ability to act as an advocate where the decision is separate from the being (Shotter, 2017). In other words, under the hermeneutical ethical framework the decision maker acts in the company's best interest by serving as the company's moral compass.

\section{HYPOTHESES DEVELOPMENT}

We start by testing the implications inferred by the four hypotheses presented by Keller et al. (2007, 305-306):

H1: "There are significant differences in ethical frameworks between males and females."

H2: There are significant differences in ethical frameworks related to level of education.

H3: "The strength of the religious ethic will be significantly different from other frameworks by which students make ethical decisions."

H4: "Students with work experience will have significantly different ethical frameworks from those without work experience."

$\mathrm{H} 1, \mathrm{H} 3$, and $\mathrm{H} 4$ are presented in quotes because they are identical to the hypotheses presented in Keller et al. (2007). $\mathrm{H} 2$ is not identical to Keller et al. because they measure education as graduate versus non-graduate while we measure education as the number of semesters of undergraduate work.

Keller et al. (2007) make and defend their predictions in hypotheses $\mathrm{H} 1-\mathrm{H} 4$ based on theory and findings in the extant literature. Examples of Keller et al. (2007)'s predictions corresponding to cited literature include: 
Gender

Education

Religious
- Franke, Crown, \& Spake (1996), and Ones \& Viswesvaran (1998)

- Veit \& Murphy (1996)

- Clark \& Dawson (1996), Fort (1997), and Kennedy \& Lawton (1996)

Work experience - Deshpandle (1997)

The cultural divide between the US and Mexico is well established in the literature. Hofstede (1980; 2001) documented differences between Mexico and the US in power distance, individualism/collectivism, and uncertainty avoidance. In a study published soon after the implementation of NAFTA in 1994, Hood \& Logsdon (2002) predict that there will be a greater appreciation of rules based ethical standards in Mexico due a higher level of uncertainty avoidance and that the higher level of power distance in Mexico could lead to ethical issues because there would be less questioning of superiors in Mexico. It is also documented in the more recent literature that one of the cultural differences documented by Hofstede $(1980 ; 2001)$, power distance, may have mitigated over time (e.g., Stammerjohan, Leach, \& Stammerjohan, 2015; and Anderson 2018, who both find evidence that the differences in power distance between US and Mexican samples are no longer significant). The remaining difference is cultural factors, the potential impact of cultural factors on ethical decision making, and the possibilities that some of the cultural factors may have changed over time make it important to examine the impact of culture on ethical decision making; and to conduct that investigation with a recent sample.

$\mathrm{H} 5$ addresses the main purpose of this study by addressing the cultural differences in ethical frameworks/ethical reasoning between the US sample employed by Keller et al. (2007) and the Mexican sample employed in this study. Given that this research question is exploratory, hypothesis $\mathrm{H} 5$ is stated in the null form.

H5: There will be no significant differences in the ethical frameworks/reasoning between US and Mexican samples.

\section{DATA AND METHODOLOGY}

To test the propositions listed above, we surveyed undergraduate Mexican college students enrolled in a business major at the Instituto Tecnologico de Estudios Superiores de Monterrey (ITESM) in the Cuernavaca campus. Permission was given by the school's Director and thus three classes of students were surveyed. The students were encouraged to participate in the survey by the respective instructors so that all students present in the classroom completed the questionnaire.

With this study we can understand the framework of ethics that future managers will bring to the workplace. This campus is located one hour south of Mexico City. By selecting Cuernavaca, with a location in the interior of the country, we hoped to eliminate the culture transfer discussed by Husted, Dozier, McMahon \& Kattan (1996). Our study is different from Marta, Heiss, \& Lurgio (2008) in that we test future managers to give multinational corporations and researchers a potential forecast of future events. While Marta et al. (2008) studied Mexican managers working in marketing, our research uses college students that will make up job applicants in the future representing prospective future managers.

The survey is adapted from Keller et al. (2007). Like Keller et al., we test six theoretical frameworks with two statements concerning ethics for each framework. A five-point Likert scale is used anchored on strongly agree and strongly disagree. The questions are presented in Appendix A in English. The Spanish versions are available from the authors on request. The questionnaire also includes demographic questions.

The six ethical frameworks, variable names, and a brief description of each framework are as follows:

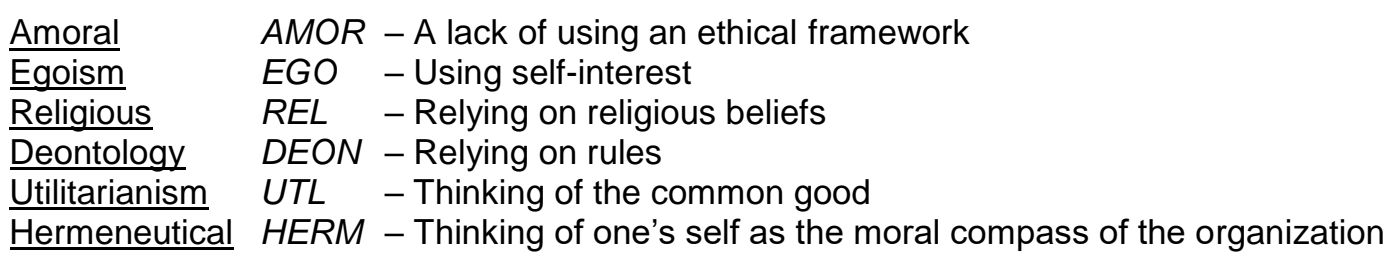

While we remained consistent with Keller et al. (2007) in the data collection stage and code the ethical questions with one as strongly agree, three as indifferent, and five as strongly disagree, we transformed the data to provide 
for ease of interpretation. Our transformed ethical framework variables are centered on zero for indifference, with positive numbers for agreement and negative numbers for disagreement. This transformation has no impact on the framework differences, standard deviations, and/or standard errors.

The questionnaire was first prepared in English and then translated into Spanish and back translated into English. Inconsistencies in the two versions were resolved by two individuals who are competent in both English and Spanish (please see, Brislin, 1980 for a description and defense of this method).

Table 1 presents the descriptive statistics. $55.6 \%$ of the sample is male, the average age is just over 19 years and the average education is three semesters of college work. While the average subject had four months of work experience, there is a wide range with only $24.2 \%$ indicating any work experience. The question numbers are the individual questions used to calculate the individual Ethical framework scores. The scores were transformed so that positive scores indicate agreement, negative scores indicate disagreement, and zero indicates indifference. In all but one case, UTL, the individual question scores were both on the same side of indifference (zero). Except for current survey question 1, all questions produce the full range of possible transformed scores, -2 to +2 . The two question scores are summed to measure each ethical framework variable which results in a theoretical range of -4 to +4 . The analysis and results section is performed using these summed ethical framework scores.

Table 1: Descriptive Statistics

\begin{tabular}{ccccccc} 
& Variable & $\mathrm{N}$ & Mean & Stdev. & Min & Max \\
\cline { 2 - 7 } & GEN & 153 & $55.6 \%$ & 0.499 & 0 & 1 \\
& AGE & 153 & 19.37 & 1.960 & 17 & 27 \\
& SEM & 149 & 2.99 & 2.431 & 1 & 9 \\
& WORK & 153 & 4.07 & 13.280 & 0 & 117 \\
& WRKD & 153 & $24.2 \%$ & 0.430 & 0 & 1 \\
\cline { 2 - 7 } Question & & & & & & \\
\hline 3 & Variable & & Mean & Stdev. & Min & Max \\
\hline 5 & AMOR & 151 & -0.053 & 1.150 & -2 & 2 \\
\hline 11 & AMOR & 152 & -0.401 & 0.934 & -2 & 2 \\
\hline 12 & EGO & 153 & -0.811 & 1.002 & -2 & 2 \\
\hline 4 & EGO & 153 & -0.020 & 1.122 & -2 & 2 \\
\hline 7 & REL & 153 & -0.425 & 1.187 & -2 & 2 \\
\hline 6 & $R E L$ & 152 & -0.388 & 1.267 & -2 & 2 \\
\hline 1 & $D E O N$ & 153 & 0.366 & 1.077 & -2 & 2 \\
10 & $D E O N$ & 152 & 0.842 & 0.859 & -2 & 2 \\
\hline 2 & UTL & 153 & 1.248 & 0.778 & -1 & 2 \\
8 & UTL & 151 & -0.232 & 1.220 & -2 & 2 \\
\hline & $H E R M$ & 150 & 0.840 & 0.865 & -2 & 2 \\
\hline
\end{tabular}

GEN is coded 1 for male, AGE is in years, SEM is the number of semesters of college, WORK is the months of work experience, and WRKD is coded 1 if $W O R K>0$.

The question numbers are the individual questions numbers from the current instrument. The mean question scores are transformed so that scores greater than zero indicate agreement and negative scores indicate disagreement.

\section{ANALYSIS AND RESULTS}

The results from the primary tests of hypotheses $\mathrm{H} 1, \mathrm{H} 2$, and $\mathrm{H} 4$ are presented in correlations reported in Table 2. Similar to Keller et al. (2007) we find very little support for the influence of gender (H1). Keller et al. (2007) found that females were more likely to rely on religious frameworks and the current study finds that females are less likely to make ethical decision without any frameworks (AMOR). While Keller et al. (2007) found little influence from education $(\mathrm{H} 2)$ and work experience $(\mathrm{H} 4)$ on frameworks other than religion, we found no significant influence from either education or work experience. Un-tabulated regression analysis results fully support the correlation results. 
Table 2: Correlation of Agreement on Ethical frameworks

\begin{tabular}{|c|c|c|c|c|c|c|c|c|c|c|}
\hline & GEN & $A G E$ & SEM & $W R K D$ & $A M O R$ & $E G O$ & $R E L$ & DEON & UTL & HERM \\
\hline GEN & 1 & & & & & & & & & \\
\hline$A G E$ & -0.052 & 1 & & & & & & & & \\
\hline SEM & 0.070 & 0.780 & 1 & & & & & & & \\
\hline WRKD & 0.014 & 0.260 & 0.2324 & 1 & & & & & & \\
\hline$A M O R$ & -0.321 & 0.043 & 0.055 & -0.076 & 1 & & & & & \\
\hline EGO & -0.119 & -0.049 & -0.127 & -0.162 & 0.493 & 1 & & & & \\
\hline REL & 0.058 & -0.037 & -0.034 & 0.072 & -0.028 & -0.004 & 1 & & & \\
\hline DEON & -0.032 & -0.045 & -0.006 & -0.006 & 0.181 & 0.109 & 0.079 & 1 & & \\
\hline UTL & 0.046 & -0.110 & -0.059 & -0.114 & 0.105 & 0.218 & 0.027 & 0.219 & 1 & \\
\hline HERM & 0.087 & 0.152 & 0.112 & 0.087 & -0.276 & -0.172 & -0.024 & 0.234 & 0.046 & 1 \\
\hline
\end{tabular}

Correlations significant at $\mathrm{p} \leq 0.05$ are reported in bold.

As would be expected, age, education level, and work are significantly correlated. Also, as might be expected, several of the ethical frameworks are significantly correlated. Those who do not rely on ethical frameworks (AMOR), are more likely to think of their own best interest (EGO), more likely to rely on rules (DEON), and less likely to see themselves as the moral compass of the organization (HERM). Oddly, those thinking of their own interest (EGO), were more likely to think of the common good (UTL), but as would be expected, less likely to see themselves as the moral compass of the organization (HERM). Those thinking of the common good (UTL) and those seeing themselves as the moral compass of the organization (HERM) were more likely to rely on rules (DEON).

Hypothesis $\mathrm{H} 3$, the strength of religious influence, and hypothesis $\mathrm{H} 5$, the influence of culture between the US and Mexico are tested by a series of t-tests reported in Table 3, and by a set of rankings reported in Table 4 . While Keller et al. (2007) found support for the reliance on religion, $\mathrm{H} 3$, in their US sample, the current study finds little reliance on religion, $\mathrm{H} 3$, and strong support for the influence of culture, hypothesis $\mathrm{H} 5$. Once the variables are transformed such that indifference is zero, the only cultural factor significantly indicating agreement with the underlying questions in the Keller et al. (2007) sample is religion (REL). Two of the ethical factors in Keller et al., Utilitarianism and Hermeneutical (UTL, HERM), are not significantly different from zero while the three remaining factors, Amoral, Egoism, and Deontology (AMOR, EGO, DEON) show significant disagreement. Our Mexican results produced significant levels of agreement on three factors, Deontology, Utilitarianism, and Hermeneutical, (DEON, UTL, HERM), and significant levels of disagreement on three factors, Amoral, Egoism, and Religion, (AMOR, EGO, REL).

The significant differences between the Keller et al. (2007) results and the current results provide evidence that future managers in Mexico may rely on a much different set of frameworks in making ethical decisions. The Mexican subjects were less likely to rely on the non-ethical framework (AMOR), more likely to think of themselves (EGO), but less likely to rely on religion (REL). The Mexican subjects were also more likely to rely on rules (DEON), to think of the common good (UTL), and to think of themselves as the moral compass of the organization (HERM).

Table 4 presents an ordered set of rankings among the six sets of ethical frameworks. Once again, these results provide strong evidence in support of hypothesis $\mathrm{H} 5$, the influence of culture. Panel A presents the rank order for the Mexican sample and Panel B presents the rank order for the Keller et al. (2007) results. The first column presents the mean scores and the numbers in the body of the table represent the difference in mean scores between the variable in the left column and the variable in the top row, e.g., -0.762 is the difference between the average HERM score of 1.973 and the average DEON score of 1.211 in the Mexican sample. Means significantly different from zero and sample differences (US v. Mexico) significant at $p \leq 0.05$ are reported in bold.

Table 3: Sample Differences in Ethical frameworks

\begin{tabular}{ccc}
\hline Mexican Sample & KSS Sample $^{1}$ & MX v. KSS
\end{tabular}




\begin{tabular}{|c|c|c|c|c|c|c|c|c|c|}
\hline Var. & $\mathrm{N}$ & $\begin{array}{c}\text { Mean } \\
\text { Std. Dev. }\end{array}$ & $\begin{array}{l}\text { t-stat. }^{2} \\
\text { p-value }\end{array}$ & $\mathrm{N}$ & $\begin{array}{c}\text { Mean } \\
\text { Std. Dev. }\end{array}$ & $\begin{array}{l}\text { t-stat. }^{2} \\
\text { p-value }\end{array}$ & Diff. & t-stat. ${ }^{3}$ & p-val. \\
\hline \multirow{2}{*}{$A M O R$} & \multirow{2}{*}{150} & -0.447 & -3.158 & \multirow{2}{*}{171} & -3.462 & -60.087 & \multirow[t]{2}{*}{3.015} & \multirow[t]{2}{*}{19.74} & \multirow[t]{2}{*}{0.000} \\
\hline & & 1.732 & 0.002 & & 0.753 & 0.000 & & & \\
\hline \multirow{2}{*}{$E G O$} & \multirow{2}{*}{153} & -0.830 & -5.641 & \multirow{2}{*}{171} & -2.509 & -27.231 & \multirow[t]{2}{*}{1.679} & \multirow[t]{2}{*}{9.67} & \multirow[t]{2}{*}{0.000} \\
\hline & & 1.820 & 0.000 & & 1.205 & 0.000 & & & \\
\hline \multirow{2}{*}{$R E L$} & \multirow{2}{*}{152} & -0.822 & -5.003 & \multirow{2}{*}{171} & 0.684 & 3.973 & \multirow[t]{2}{*}{-1.507} & \multirow[t]{2}{*}{-6.33} & \multirow[t]{2}{*}{0.000} \\
\hline & & 2.027 & 0.000 & & 2.252 & 0.000 & & & \\
\hline \multirow{2}{*}{$D E O N$} & \multirow{2}{*}{152} & 1.211 & 9.899 & \multirow{2}{*}{171} & -1.251 & -11.887 & \multirow[t]{2}{*}{2.462} & \multirow[t]{2}{*}{15.26} & \multirow[t]{2}{*}{0.000} \\
\hline & & 1.508 & 0.000 & & 1.377 & 0.000 & & & \\
\hline \multirow{2}{*}{ UTL } & \multirow{2}{*}{151} & 1.013 & 8.661 & \multirow{2}{*}{171} & -0.129 & -1.337 & \multirow[t]{2}{*}{1.142} & \multirow[t]{2}{*}{7.54} & \multirow[t]{2}{*}{0.000} \\
\hline & & 1.438 & 0.000 & & 1.258 & 0.183 & & & \\
\hline \multirow{2}{*}{ HERM } & \multirow{2}{*}{147} & 1.973 & 16.418 & \multirow{2}{*}{171} & -0.023 & -0.210 & \multirow[t]{2}{*}{1.996} & \multirow[t]{2}{*}{12.17} & \multirow[t]{2}{*}{0.000} \\
\hline & & 1.457 & 0.000 & & 1.459 & 0.834 & & & \\
\hline
\end{tabular}

${ }^{1}$ The Keller, Smith and Smith (2007) values are transformed in the same way that our values are transformed, i.e., larger positive values are now associated with greater agreement with the item questions and more negative numbers are now associated with greater disagreement.

\begin{abstract}
${ }^{2}$ The $t$-statistics and $p$-values reported for each sample ethical framework score are reported in reference to the scale mid value of zero, i.e., an average score greater than zero indicates agreement with the item questions and an average score less than zero indicates disagreement with the item questions

${ }^{3}$ The t-statistics and p-values reported for the differences are based on the assumption of unequal variances in the samples.
\end{abstract}
Mean scores different from 0 and between study differences significant at $p \leq 0.05$ are reported in bold.

While ethical reasoning in the Keller et al. (2007) US sample is dominated by reliance on religious frameworks (REL), the current Mexican sample is dominated by a belief that one should act as the moral compass of the organization (HERM). Although HERM ranked second in Keller et al., the transformed score of -0.023 indicates indifference and is not significantly different from thinking of one's self (EGO). The overall finding of Keller et al. is that their subjects were not opposed to relying on an ethical framework, did not think of themselves, did not rely on rules, but did rely on religious frameworks. The current Mexican sample, in contrast, indicates a reliance on behaving as the moral compass, relying on rules, thinking of the common good in making ethical decisions.

\title{
6. DISCUSSION AND MANAGERIAL IMPLICATIONS
}

While the current study is not designed to test whether future Mexican managers will be more or less ethical than their US counterparts, it is interesting to note that as opposed to the perceptions of US subjects in Khera (2010) who believed that Mexicans would be less ethical, some recent studies have shown Mexican subjects to be more ethical than corresponding US subjects (e.g., Anderson, 2018). What the current study does clearly show is that there are significant differences between US and Mexican college students in the ethical frameworks they rely on for making ethical decisions, and that there are far greater differences based on US v. Mexico than differences that can be explained by the theoretical factors proposed by Keller et al. (2007), gender, education level, and work experience.

The current study also shows that Mexicans rely far less on religion in making ethical decisions. Although not central to the current study, it is also interesting to note the findings of Beekun \& Westerman (2012) who found in a study of Norwegian and US college students that while the US students were more spiritual, the Norwegians were more ethical. Furthermore, while spiritual and ethical were positively correlated among the Norwegians, the opposite was true among their US counterparts. Another finding of the current study is consistent with Hood 
\& Logsdon (2002) who predicted that Mexicans would be more comfortable with rules. Our findings on the reliance on the Deontology framework supports this expectation.

Table 4: Ethical framework Score Rankings and Differences

Panel A: Mexican Sample

\begin{tabular}{|c|c|c|c|c|c|c|c|}
\hline & & HERM & $D E O N$ & UTL & $A M O R$ & $R E L$ & $E G O$ \\
\hline & Mean & 1.973 & 1.211 & 1.013 & -0.447 & -0.822 & -0.830 \\
\hline HERM & 1.973 & na & & & & & \\
\hline$D E O N$ & 1.211 & -0.762 & na & & & & \\
\hline UTL & 1.013 & -0.960 & -0.197 & na & & & \\
\hline$A M O R$ & -0.447 & -2.419 & -1.657 & -1.460 & na & & \\
\hline$R E L$ & -0.822 & -2.795 & -2.033 & -1.836 & -0.376 & na & \\
\hline$E G O$ & -0.830 & -2.803 & -2.041 & -1.843 & -0.383 & -0.008 & na \\
\hline
\end{tabular}

Panel B: KSS Sample ${ }^{1}$

\begin{tabular}{|c|c|c|c|c|c|c|c|}
\hline & & $R E L$ & HERM & UTL & DEON & $E G O$ & $A M O R$ \\
\hline & Mean & 0.684 & -0.023 & -0.129 & -1.251 & -2.509 & -3.462 \\
\hline$R E L$ & 0.684 & na & & & & & \\
\hline HERM & -0.023 & -0.707 & na & & & & \\
\hline UTL & -0.129 & -0.813 & -0.106 & na & & & \\
\hline$D E O N$ & -1.251 & -1.935 & -1.228 & -1.122 & na & & \\
\hline$E G O$ & -2.509 & -3.193 & -2.486 & -2.380 & -1.258 & na & \\
\hline$A M O R$ & -3.462 & -4.176 & -3.439 & -3.333 & -2.211 & -0.953 & na \\
\hline
\end{tabular}

${ }^{1}$ The Keller, Smith and Smith (2007) values are transformed in the same way that the current values are transformed, i.e., larger positive values are now associated with greater agreement with the item questions and more negative numbers are now associated with greater disagreement.

Mean scores and differences significant at $\mathrm{p} \leq 0.05$ are reported in bold.

As a whole, the findings of this study in conjunction with the findings of other recent studies have several managerial implications for US companies doing business in or with Mexico. Recent findings suggest that preconceived ideas about the ethical levels in Mexico may be misleading. Furthermore, the differences in ethical frameworks documented in this study could have implications for training and establishing an ethical work environment in Mexico. The reliance on rules, on the Deontology framework, suggest that corporate [or business] codes of ethics may be even more effective in Mexico. The findings also suggest that we should expect Mexicans to rely less on religion to form a basis of ethical reasoning, to be more inclined to consider the common good and more inclined to believe that they should act as the moral compass of their organization.

\section{CONCLUSIONS, LIMITATIONS, AND FUTURE RESEARCH}

There can be no doubt that ethics will remain an ongoing area of interest for business and academics both within the US, and for countries where US companies may operate or conduct business. Furthermore, there can be no doubt about the importance of Mexico and the need to understand the impact of cultural difference and how that may affect ethical decisions by current and future Mexican managers.

The current study does have limitations. First, several differences between the current sample of Mexican business students and the accounting students employed by Keller et al. (2007) used for comparison should be considered in interpreting the results. The students in the current sample were business instead of accounting, earlier in their college careers, and included fewer subjects with work experience (24.2\% v. $45.0 \%)$. However, given the relative strength of the current culture results (US v. Mexico), compared to little or no affects found for education level and work experience by either the current study or Keller et al., we feel confident that the culture 
results are not solely driven by differences in the samples. Second, like all survey research we are dependent on the truthfulness of the answers and can only assume that our sample sheds light on the target population: future Mexican managers.

The area of ethics, ethical decision making, and the influences of culture continue to offer many avenues for future research. The present study helps to provide a more concise framework for that continued research. The next logical step could be to further explore the possible connections between ethical frameworks and ethical actions. Additionally, future researchers could also attempt a meta-analysis of multinational and multicultural business ethics and the effects on international management.

\section{REFERENCES}

Anderson, M. A. (2018). Assessing the correlation of culture with business ethics of company managers in the United States and Mexico. Ethical standards and practice in international relations, Topor, F. S. (Ed.) 73-99, IGI Global.

Ardelean, A. (2015). Study regarding the clarification of ethical dilemmas in financial audit. Audit Financiar 13(125), 75-90.

Beekun, R. \& Westerman, J. (2012). Spirituality and national culture as antecedents to ethical decision-making: A comparison between the United States and Norway. Journal of Business Ethics, 110(1), 33-44.

Brislin, R.W. (1980). Translation and content analysis of oral and written material. Handbook of cross-cultural psychology: Methodology, Triandis, H.C. J.W. and Berry. (Eds.) Allyn and Bacon, Boston, 389-444.

Clark, J.W. \& Dawson, L. E. (1996). Personal religiousness and ethical judgments: An empirical analysis. Journal of Business Ethics, 15(3), 359-72.

Deshpande, S.P. (1997). Managers' perception of proper ethical conduct: The effect of sex, age, and level of education. Journal of Business Ethics, 16(1), 79-85.

Doh, J., Husted, B., Matten, D. \& Santoro, M. (2010). Ahoy there! Toward greater congruence and synergy between international business and business ethics theory and research. Business Ethics Quarterly, 20(3), 481-502.

Epstein, M.J. \& Spalding, A. D. (1993). The accountant's guide to legal liability and ethics, Irwin: Homewood, IL.

Fort, T.L. (1997). Religion and business ethics: The lessons from political morality. Journal of Business Ethics, 16(3), 263273.

Franke, G. \& Nadler, S. (2008). Culture, economic development, and national ethical attitudes. Journal of Business Research, 61(3), 254-264.

Franke, G., Crown, D. F. \& Spake, D. F. (1996). Gender differences in ethical perceptions of business practices: A social role theory perspective. Journal of Applied Psychology, 82(6), 920-934.

Frederiksen, C. S. (2012). The presentation of utilitarianism within the field of business ethics. Journal of Business Ethics Education, 9(1), 193-214.

Garrett, T. M. (2016). Ethics and a faith-inspired solution to the problem of economism. Review of Social Economy, 74(2), 129-147.

Hofstede, G. (1980). Culture's consequences: International differences in work-related values, Sage: Newbury Park, CA.

Hofstede, G. (2001). Culture's consequences: Comparing values, behaviors, institutions, and organizations across nations (2nd ed.). Thousand Oaks, CA: Sage.

Holland, D. \& Albrecht, C. (2013). The worldwide academic field of business ethics: Scholars' perceptions of the most important issues. Journal of Business Ethics, 117(4), 777-788.

Hood, J. N. \& Logsdon, J. M. (2002). Business ethics in the NAFTA countries: A cross-cultural comparison. Journal of Business Research 55(10), 883-890.

Husted, B.W., Dozier, J. B., McMahon, J. T. \& Kattan, M. W. (1996). The impact of cross-national carriers of business ethics on attitudes about questionable practices and form of moral reasoning. Journal of Business Studies 27(2), 391-411.

Keller, A. C., Smith, K. T. \& Smith, L. M. (2007). Do gender, educational level, religiosity, and work experience affect the ethical decision-making of U.S. accountants? Critical Perspectives on Accounting, 18, 299-314.

Kennedy, E.J. \& Lawton, L. (1996). The effects of social and moral integration on ethical standards: a comparison of American and Ukrainian business students. Journal of Business Ethics, 15(8), 901-911.

Khalid, K., Eldakak, S. E. \& Loke, S. (2017). A structural approach to ethical reasoning: The integration of moral philosophy. Academy of Strategic Management Journal, 16(1), 81-113.

Khera, I. (2010). Ethics perceptions of the U.S. and its large developing-country trading partners. Global Management Journal, 2(1), 33-41.

Marta, J., Heiss, C. M. \& De Lurgio, S. A. (2008). An exploratory comparison of ethical perceptions of Mexican and U.S. Marketers. Journal of Business Ethics, 82(3), 539-555.

Melé, D. (2015). Religious approaches on business ethics. Journal of Applied Ethics, 6, 137-160. 
Moehler, M. (2013). Contractarian ethics and Harsanyi's two justifications of utilitarianism. Politics, Philosophy and Economics, February 12(1), 24-47.

Ones, D. S. \& Viswesvaran, C. (1998). Gender, age, and race differences on overt integrity tests: results across four largescale job applicant data sets. Journal of Applied Psychology, 83(1), 35-42.

Shotter, J. (2017). Persons as dialogical-hermeneutical-relational beings - New circumstances 'call out' new responses from us. New Ideas in Psychology, January 44, 34-40.

Stammerjohan, W. W., Leach, M. A., \& Stammerjohan, C. A. (2015). The moderating effects of power distance on the budgetary participation-performance relationship. Advances in Management Accounting, 25, 103-148.

$\mathrm{Su}$, S. (2006). Cultural differences in determining the ethical perception and decision- making of future accounting professionals: A comparison between accounting students from Taiwan and the United States. The Journal of American Academy of Business, 9(1), 147-158.

Veit E.T. \& Murphy, M. R. (1996). Ethics violations: A survey of investment analysts. Journal of Business Ethics, 15(12), 1287-1297.

Vodonick, J. (2016). Pragmatism-beyond epistemology: An ethical approach to systems decision process. Journal of Organizational Transformation \& Social Change, 13(1), 43-53.

Vodonick, J. (2017). Neo-pragmatism: An ethical anticipatory system. European Journal of Futures Research, 5 (1), 1-7.

\section{APPENDIX 1. SURVEY INSTRUMENT}

The following questions are intended to identify what outcomes you expect from work, and how you feel you should act in the workplace. To what extent do you agree or disagree with the following statements?

Scales: 1 = Strongly Agree, $2=$ Agree, $3=$ Neutral, $4=$ Disagree, $5=$ strongly Disagree

$\begin{array}{cccccc}\text { 1) } & \text { SAgree } & \text { A } & \text { N } & \text { D } & \text { SDisagree } \\ \text { 1) } & 1 & 2 & 3 & 4 & 5 \\ & & & & & \\ \text { 2) } & 1 & 2 & 3 & 4 & 5 \\ & & & & & \\ \text { 3) } & 1 & 2 & 3 & 4 & 5 \\ \text { 4) } & 1 & 2 & 3 & 4 & 5 \\ \text { 5) } & 1 & 2 & 3 & 4 & 5 \\ \text { 6) } & 1 & 2 & 3 & 4 & 5\end{array}$

When I make decisions, I take into consideration the impact my decision will have on the people affected and choose what seems to be right for most of them.

There is truth contained in a company's records. It will be my duty to reflect this truth no matter the consequences.

Ethics are important, but a business manager's job is to manage the business.

I derive my ethical beliefs from deep religious values.

The marketplace provides the truth by which businesses survive. Managing a business is about truth, not ethics.

The ethical questions that confront most managers would be simplified, or even eliminated, if they would just follow existing laws and regulations.



If I have time, I seek the guidance of a religious person or text as a way of finding answers to ethical dilemmas.

My greatest ethical duty as a business manager is to present the truth as the company's records, and the evidence, dictates.

9) $\begin{array}{lllll}1 & 2 & 3 & 4 & 5\end{array}$

10) $1 \quad 2 \quad 3 \quad 4 \quad 4 \quad 5$

11) $1 \quad 2 \quad 35 \quad 4 \quad 5$

12) $1 \quad 2 \quad 3 \quad 4 \quad 5$

I follow rules that are set down, and I seek for rules that govern all ethical situations.

What is best for the greatest number of people is ethical. My ethical judgement is based on what is good for me. What is best for me is what I will always choose. 